УДК 621.316 .71

\title{
ТЕХНИЧЕСКИЕ РЕШЕНИЯ ПО ОЦЕНКЕ УРОВНЯ ЖИДКОСТИ В НЕФТЕДОБЫВАЮЩИХ И ВОДОЗАБОРНЫХ СКВАЖИНАХ
}

\author{
Денисламов Ильдар Зафирович1, \\ denislamoviz@mail.ru
}

\author{
Гималтдинов Ильяс Кадирович1,2, \\ iljas_g@mail.ru
}

\author{
Якубов Равиль Наилевич1 \\ rnyakubov@gmail.com
}

\author{
Денисламова Алия Ильдаровна 1 , \\ denislamova2014alia@mail.ru \\ 1 Уфимского государственного нефтяного технического университета, \\ Россия, 450062, г. Уфра, ул. Космонавтов, 1. \\ 2 Академии Наук Республики Башкортостан, \\ Россия, 450008, г. Уфа, ул. Кирова, 15.
}

\begin{abstract}
Актуальность исследования следует из необходимости оценки динамического уровня жидкости в нефртедобывающих и водозаборных скважинах с необходимой частотой. Измерения уровня жидкости в скважинах различного назначения необходимы для контроля разработки нефртяной залежи, оценки эфффективности воздействия на продуктивный пласт и обеспечения безаварийной эксплуатации глубинного скважинного насоса. Информация об уровне жидкости востребована несколькими службами нефтегазодобывающего предприятия, а выполнение таких измерений может рассматриваться как одна из фуннций интеллектуальной скважины.

Цель: поиск и обоснование альтернативных методов определения уровня жидкости в межтрубном пространстве нефртедобывающих и водозаборных скважин. Измерения должны проводиться с необходимой периодичностью без привлечения персонала предприятия в скважинную зону.

Объектом исследования являются нефтедобывающие и водозаборные скважины, снабженные датчиками давления, генераторами и приемниками акустических волн и вторичными приборами по передаче скважиной информации на рабочие места персонала предприятия.

Методы исследования основаны на общеизвестных законах физической гидродинамики и методах математической статистики.

В результате исследования установлено, что звукометрический метод определения динамического уровня жидкости в межтрубном пространстве скважины имеет погрешность измерений в действующих нефтедобывающих скважинах из-за непостоянства состава попутного нефртяного газа по времени эксплуатации скважины и по глубине насосно-компрессорных труб на фиксированный момент времени. Предложены альтернативные методы измерений, основанные на генерации акустических волн в различных средах и измерении давления в межтрубном пространстве по датчикам на стационарной основе.
\end{abstract}

\section{Ключевые слова:}

Состав газа, скважина, межтрубное пространство, уровень жидкости, датчик давления, электроцентробежный насос, насосно-компрессорная труба, звуковая волна.

\section{Введение}

Подавляющее большинство нефтедобывающих и водозаборных скважин эксплуатируются с помощью глубинного насосного оборудования, которое должно иметь определенную производительность и устанавливаться на расчетной глубине относительно устья скважины и продуктивного пласта. Как правило, совокупность этих технических решений и обеспечивает сбалансированность системы «пласт-скважинанасос», когда приток жидкости из пласта в скважину соответствует производительности глубинного насоса Нефтедобывающие и водозаборные скважины нефтяных компаний России оборудованы в подавляющем большинстве электроцентробежными насосами и штанговыми плунжерными установками. Несмотря на разный принцип действия, оба вида насосов весьма чувствительны к величине давления флюидов на вхо- де в насос. Насосное оборудование рассчитано на транспортировку жидкости, в которой содержание газовой фазы может находиться лишь в определенных пределах. Например, для глубинной электроцентробежной установки по одним источникам $[1,2]$ содержание свободного газа в зоне приемных отверстий насоса не должно превышать 25-30 \%, а по другим данным [3] даже содержание свободного газа в пределах 30-40\% от объема газожидкостного состава может быть оптимальным для работы установки. Содержание свободного газа (ССГ) на приеме насоса в свою очередь зависит от давления в рассматриваемой точке. Это давление формируется как сумма давления попутного нефтяного газа над уровнем жидкости и гидростатического давления столба жидкости в межтрубном пространстве от уровня жидкости до приема насоса. Этими положениями и руководству- 
ются при выборе глубины спуска насоса и его погружения под динамический уровень жидкости. Во всех этих расчетах всегда остается неизвестной величиной плотность газожидкостного состава (ГЖС) в межтрубном пространстве (МП) скважины. По экспертным оценкам $[4,5]$ рассматриваемая плотность ГЖС в нефтедобывающих скважинах может быть

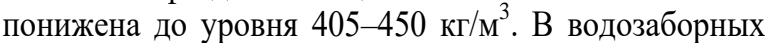
скважинах с низким газовым фактором плотность может быть выше $1000 \mathrm{\kappa r} / \mathrm{m}^{3}$.

Оценка динамического уровня жидкости в скважине по данным термо-манометрической системы (TMC) и устьевого давления из-за неопределенности плотности газожидкостного состава в МП скважины остается сложной проблемой.

Скважины с ТMC в некоторых компаниях составляют более половины фонда добывающих скважин, но их нет в скважинах со штанговыми плунжерными насосами из-за отсутствия линии обратной связи до устьевой зоны. В данной работе рассматриваются некоторые способы определения положения динамического уровня жидкости в скважине.

\section{Определение уровня жидкости в скважинах звукометрическим способом}

Данный метод испытан временем и предельно усовершенствован, он стал достаточно безопасным, доступным и более точным, чем десятилетия назад. Метод основан на генерации акустической волны на устье скважины переносным или стационарным устройством, распространении волны в межтрубном пространстве, отражении от раздела сред - динамического уровня жидкости и вторичной фиксации этой волны на устье скважины приемным устройством. Генератор и приемник акустической волны совмещены в удобном и компактном устройстве серии Микон или Суддос, а сам метод и его реализация в автоматическом режиме применения описаны в работах [6-10]

В работах [11-14] авторы указывают на то, что скорость звуковой волны в попутном нефтяном газе зависит от давления газа, его компонентного состава и структуры газовой среды вблизи контакта с жидкой фазой. Известно, что межтрубное пространство нефтедобывающей скважины в нижней части сообщается с помощью глубинного насоса с колонной насосно-компресорных труб (НКТ) и с продуктивным пластом - через перфорационные отверстия в обсадной колонне скважины. В верхней части межтрубное пространство периодически сообщается с системой нефтесбора, когда давление в газовой среде превышает давление в выкидной линии скважины. Перепуски попутного нефтяного газа (ПНГ) из скважины в систему нефтесбора носят хаотический характер и зависят в основном от сбалансированности системы «пласт-скважина-насос». Периодически операторы по добыче нефти выпускают в атмосферу ПНГ из МП скважины для снижения содержания свободного газа на приеме электроцентробежного насоса и стабилизации его работы. Описанные процессы не регламентируются производственными документами, происходят в произвольном порядке, поэтому состав ПНГ в межтрубном пространстве на момент производства измерения динамического уровня жидкости звукометрическим методом не является известным фактором. Измерения уровня жидкости при разных давлениях в МП, а значит и в отличных условиях сепарации легких углеводородов из нефти в газовую среду, показали, что разница в измеренных уровнях жидкости достигает 147 м в интервале 1426-1573 м [6].

В работах [15-17] рассмотрены способы повышения точности измерения уровня жидкости, основанные на использовании акустических волн различной частоты и интерпретации результатов с помощью математических методов анализа частотного спектра отраженных сигналов.

Точность измерений уровня жидкости звукометрическим способом обеспечивается двумя способами:

1) непосредственным измерением скорости звука в исследуемой среде путем отбора порции попутного нефтяного газа в трубную камеру известной длины. В камеру будет отобран ПНГ из приустьевой зоны межтрубного пространства, который по составу и плотности будет отличаться от газа над уровнем жидкости. Это обуславливает повышение давления газа в МП по экспоненциальной формуле барометрического нивелирования ЛапласаБабинэ [18]. На наш взгляд, отбор дискретной пробы ПНГ не даёт объективной информации о скорости звука в исследуемой многокомпонентной газовой среде.

2) использованием реперов, установленных на известных глубинах по колонне насоснокомпрессорных труб [1]. При расположении единственного репера вблизи устья скважины или уровня жидкости способ имеет тот же недостаток, что отбор газа в длинномерный контейнер (первый способ). Логично, что реперов должно быть не менее трех: вблизи устья скважины и уровня жидкости, а также между этими крайними точками по длине колонны НКТ. В этом случае возникает вопрос о чувствительности уровнемеров серии Микон или Суддос. Наличие такой высокой чувствительности могло бы привести к идентификации каждой муфты от устья скважины до глубинного насоса, и тогда, наложив на эту информацию паспортные данные спущенной в скважину колонны труб относительно глубины муфтовых соединений, можно точно определить положение уровня жидкости.

Данное техническое решение не реализуется по двум причинам:

1) в серийных уровнемерах не обеспечена идентификация каждого муфтового соединения;

2) при монтаже и спуске колонны НКТ не ведется учет глубины уже смонтированных муфтовых соединений.

Проведенный анализ звукометрического способа оценки уровня жидкости в МП показывает, что метод достиг предела своих возможностей из-за постоянной неопределенности в компонентном составе попутного нефтяного газа как среды распространения контролируемой волны. 
В некоторых типах скважин, например наблюдательных, пьезометрических и водозаборных, состав газа и даже жидкой фазы может быть известным и неизменным в течение длительного времени. Поэтому в этой части статьи рассмотрим еще три технических решения, которые интересны с точки зрения идентификации раздела фаз: газообразной и жидкостной. В статье [11] уделено внимание структуре углеводородов вблизи раздела фаз, а в литературе часто упоминается понятие углеводородной пены над динамическим уровнем нефти в межтрубном пространстве действующей скважины. По изобретению [19] предложено положение раздела фаз фиксировать путем помещения в зону раздела зонда с положительной плавучестью. Зонд содержит два генератора волн: «медленной» акустической волны и «быстрой» электромагнитной волны.

Момент инициирования «медленной» акустической волны определяют по времени прихода на устье скважины «быстрой» электромагнитной волны благодаря их одновременной генерации на уровне жидкости. Отметим, что изобретение основано, в том числе, и на очень быстром прохождении электромагнитного сигнала от уровня жидкости до устья. Это практически невозможно осуществить в скважинах с большой кривизной ствола скважины, так как электромагнитный сигнал будет активно поглощаться металлом обсадной колонны и не проходить выше зоны кривизны скважины.

Хронологическое время инициирования акустической волны с зонда поплавка $t_{0}$ остается величиной неизвестной в случае отказа от «быстрой» электромагнитной волны, поэтому остается от этого параметра в сложившейся ситуации избавиться с помощью стандартного математического приема [20]. Для этой цели акустическую волну одновременно создают в газовой и жидкой средах и фиксируют время прихода акустической волны по газовой среде от уровня жидкости до приемника на устье скважины $-t_{\text {газ }}$ и момент времени прихода второй акустической волны - от уровня жидкости до приемника в зоне глубинной насосной установки $-t_{\text {жид. }}$ Информация по этим хронологическим временам передается на станцию управления скважины, например, от приемника в зоне насоса - по стандартному кабелю электропитания ПЭД насоса.

Схема расположения генератора акустических волн и приемников в межтрубном пространстве действующей нефтедобывающей скважины приведена на рис. 1.

Два приемника акустических волн расположены в разных концах колонны НКТ для того, чтобы в крайних положениях уровня жидкости в скважине приемники фиксировали акустические волны, а именно устьевой приемник - 8 фиксировал волны в газовой среде (в попутном нефтяном газе), а глубинный приемник - 9 фиксировал акустические волны, распространяющиеся в жидкой среде.

Способ измерения уровня осуществляется в следующем порядке:

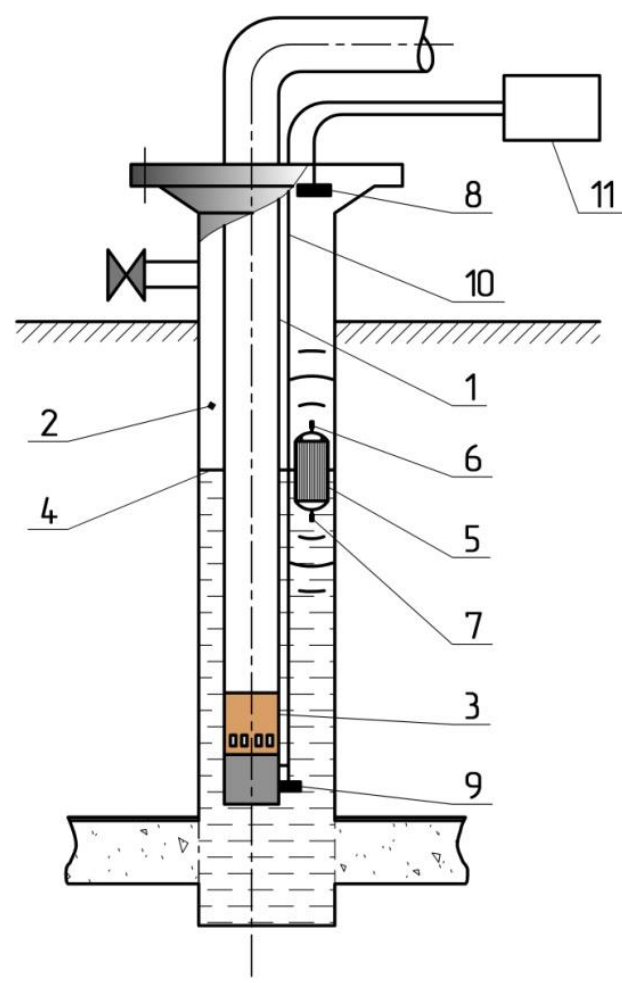

Рис. 1. Генерация акустических волн с динамического уровня жидкости скважины: 1 - насоснокомпрессорные трубы; 2 - газовая среда; 3 глубинный насос; 4 - динамический уровень жидкости в межтрубном пространстве; 5 - генератор акустических сигналов с автономной плавучестью; 6 - излучатель акустических волн в газовой среде; 7 - излучатель акустических волн в жидкостной среде; 8 - устьевой приемник акустической волны в газовой среде; 9 - приемник акустической волны в жидкостной среде; 10 - кабель электропитания с обратной информаџионной функиией; 11 - станиия управления скважины

Fig. 1. Generation of acoustic waves from a dynamic fluid level of a well: 1 - production tubing; 2 - gas environment; 3 -deep pump; 4 -dynamic fluid level in the annulus; 5 - generator of acoustic signals with autonomous buoyancy; 6 - emitter of acoustic waves in a gaseous medium; 7 -emitter of acoustic waves in a liquid medium; 8 - wellhead receiver of an acoustic wave in a gas medium; 9 - receiver of an acoustic wave in a liquid medium; 10 - pump power cable with reverse information function; 11 - well control station

1. В межтрубное пространство скважины на уровень жидкости помещают генератор - 5 в виде поплавка с положительной плавучестью в жидкостной среде. Генератор имеет плотность в пределах 400600 кг/м ${ }^{3}$ и снабжен двумя излучателями - 6, 7.

2. С необходимой частотой в течение суток, например, ежечасно, генератор - 5 инициирует одномоментно две акустические волны: в газовую среду через излучатель - 6 и в жидкостную среду - через излучатель -7 . 
3. В момент времени $t_{\text {газ }}$ приемник -8 фиксирует приход акустической волны в газе, а в момент $t_{\text {жид }}$ приемник - 9 фиксирует приход акустической волны в жидкостной среде.

4. Информация от приемников $-8,9$ передается по линии связи - 10 на станцию управления $(\mathrm{CУ})-11$.

5. По формуле контроллер станции управления определяет удаленность уровня жидкости от устья или, как принято говорить в нефтедобыче, уровень жидкости в скважине.

Обозначим условное хронологическое время одновременного излучения двух акустических волн через $t_{0}$, тогда время движения волны по газовой среде равно:

$$
t_{\text {газ }}-t_{0}=H_{\text {ур }} / v_{\text {газ }},
$$

где $t_{\text {газ }}-$ хронологическое время прихода акустической волны по газовой среде от уровня жидкости до приемника на устье скважины; $H_{\text {ур }}$ - расстояние от устья до уровня жидкости; $v_{\text {газ }}$ - скорость распространения акустической волны в газе.

Время движения акустической волны по жидкостной среде равно:

$$
t_{\text {жид }}-t_{0}=\left(H_{\text {нас }}-H_{\text {ур }}\right) v_{\text {жид }},
$$

где $t_{\text {жид }}-$ время прихода акустической волны в жидкостной среде от уровня жидкости до приемника в зоне глубинной насосной установки; $H_{\text {нас }}-$ расстояние от устья скважины до глубинной насосной уста-

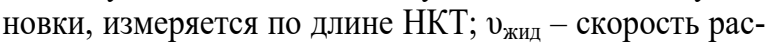
пространения акустической волны в жидкостной среде - в нефти или воде.

Из (1) и (2) следует расчетная формула (3):

$$
H_{\text {ур }}=\left(t_{\text {газ }}-t_{\text {жид }}+\frac{H_{\text {нас }}}{v_{\text {жид }}}\right) \cdot\left(\frac{v_{\text {газ }} v_{\text {жид }}}{v_{\text {газ }}+v_{\text {жид }}}\right) \cdot
$$

Рассмотрим другой способ определения уровня жидкости в скважине. Предлагается по существующей аналогии в газовой среде акустическую волну создавать в водной среде, и по времени прохождения двойного пути от насоса до динамического уровня воды в межтрубном пространстве оценивать высоту столба воды над глубинным насосом [21]. Генератор и приемник акустической волны (AB) размещают стационарно в зоне глубинного электроцентробежного насоса скважины, на уровне жидкости скважины размещают шарики, выполненные из карбамидной смолы или из материала с аналогичным свойством положительной плавучести в воде. Акустическую волну генерируют в жидкой среде в зоне глубинного насоса и измеряют время прохождения акустической волны от глубинного насоса до карбамидных шариков, находящихся на уровне жидкости, и время прохождения отраженной АВ от уровня жидкости и шариков из карбамидной смолы до приемника акустической волны в зоне глубинного насоса.

Уровень жидкости определяют по формуле:

$$
H_{\text {ур }}=H_{\text {нас }}-\frac{1}{2} \cdot v_{\text {жид }} \cdot\left(t_{2}-t_{1}\right),
$$

где $t_{1}$ - время с момента генерации акустической волны в воде в зоне глубинного насоса; $t_{2}-$ время прихода акустической волны к приемнику в зоне глубинного насоса.

Схема расположения генератора и приемника акустических волн в межтрубном пространстве действующей водозаборной скважины приведена на рис. 2.

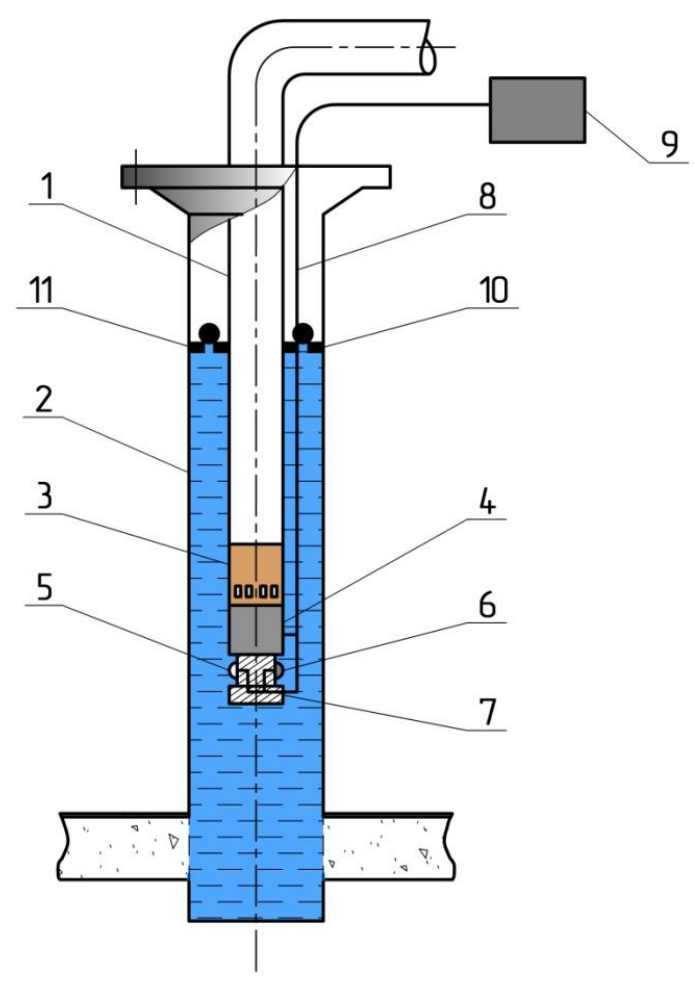

Pис. 2. Определение уровня жидкости в водозаборной скважине: 1 - колонна насосно-компрессорных труб; 2 - обсадная колонна; 3 - глубинный электроиентробежный насос с электроприводом; 4, 5 - генератор акустических волн в жидкой среде; 6 - приемник акустической волны; 7 блок преобразователя акустической информачии; 8 - кабель электропитания установки с обратной информационной функиией; 9 - станция управления скважины; 10 - шарики с положительной плавучестью в жидкости; 11 - динамический уровень воды в межтрубном пространстве

Fig. 2. Determination of fluid level in a water well: 1 tubing string; 2 - casing string; 3 - deep electric centrifugal pump with electric drive; 4, 5 -acoustic wave generator in a liquid medium; 6 - acoustic wave receiver; 7 - acoustic information transducer block; 8 - cable power supply of the installation with an inverse information function; 9 - well control station; 10 - balls with positive buoyancy in the liquid; 11-dynamic water level in the annulus

Способ измерения уровня осуществляется в следующем порядке:

1. С заданной частотой во времени генератор - 5 создает акустический импульс, а находящийся рядом приемник - 6 фиксирует момент времени инициирования этой волны $t_{1}$. 
2. Акустическая волна распространяется с известной скоростью в воде, доходит до границы раздела воды и газа - 11 , отражается от твердого препятствия в виде слоя из шариков - 10, отраженная $\mathrm{AB}$ с такой же скоростью распространяется в обратную сторону - к глубинному насосу.

3. Приемник - 6 фиксирует момент времени прихода $t_{2}$ отраженной волны в зону глубинного насоса.

4. Информация от приемников - 6 передается на блок преобразователя акустической информации - 7, усиливается, кодируется и передается по линии связи 8 на станцию управления (СУ) - 9. В качестве линии связи от блока - 7 до СУ в скважинах с глубинным электроцентробежным насосом служит кабель электропитания электродвигателя насосной установки.

5. По формуле (4) контроллер станции управления определяет удаленность уровня воды от устья.

Данный способ применим для случая, когда жидкая фаза не содержит газовые пузырьки и известна скорость распространения акустических волн в ней. Например, на территории республики Татарстан такие залежи с высоковязкой нефтью залегают на глубинах до 300 м и содержат в $1 \mathrm{~m}^{3}$ нефти не более 50 литров попутного газа [22]. Описанный способ, на наш взгляд, применим и для таких нефтяных скважин.

\section{Анализ нетрадиционных способов оценки уровня} жидкости в скважинах

Наиболее известным и ранним способом измерения уровня жидкости в скважинах с малой глубиной и в емкостном оборудовании (танки и резервуары) является технология, по которой на скребковой проволоке или геофизическом кабеле в газовую среду опускают пустотелый и герметичный снаряд малой плотности. По натяжению проволоки или кабеля судят о моменте вхождения снаряда в среду со значительно большей плотностью. При вхождении снаряда с функцией генератора акустических волн в жидкую среду (водную или нефтяную) происходит исчезновение этих волн в газовой среде, что и можно фиксировать с помощью приемника акустической волны. Способ подробно описан в отечественной и иностранной литературе $[7,23]$. Оба способа непригодны для исследования глубоких скважин, имеющих объективную пространственную кривизну относительно вертикальной составляющей.

Прямые способы измерения уровня жидкости в скважине имеют наименьшую погрешность, так как измеряющее устройство спускается непосредственно в исследуемую зону скважины, а способ определения границы раздела сред основан на разнице в свойствах попутного нефтяного газа с одной стороны, нефти и воды - с другой. Геофизические влагомеры и плотномеры основаны на разнице плотности флюидов, их электрического сопротивления и диэлектрической проницаемости [24]. Положение уровня жидкости в межтрубном пространстве, замеряемое через колонну насосно-компрессорных труб, определяют с помощью методов радиометрии по разному содержанию ядер водорода в единице объема жидкости и газа и по различной плотности этих сред [25].
Способы определения уровня жидкости, основанные на использовании спуско-подъемных операций глубинных приборов, применимы во время капитального ремонта скважин для установления герметичности обсадной колонны методом снижения уровня жидкости. Такие исследования выполняются после предварительной установки пакерующего устройства на необходимой глубине скважины. Спускоподъемные операции аналогичных приборов в действующей нефтедобывающей скважине требуют снижения давления в МП до атмосферного или применения малогабаритного лубрикатора с его фиксацией к эксцентричному отверстию в план-шайбе устьевой арматуры. Исследовательские подразделения нефтегазодобывающих компаний к настоящему времени не укомплектованы лубрикаторами для работы в межтрубном пространстве скважин.

Попутный нефтяной газ в межтрубном пространстве скважины в первом приближении можно рассматривать как идеальный газ, состояние которого в замкнутом пространстве скважины описывается уравнением Менделеева-Клапейрона. В статье [26] предложено оценивать давление и температуру газовой среды, находить объем ПНГ и высоту цилиндрического газового тела, которое и является уровнем газожидкостного раздела. Если среднее давление в газовой среде еще можно найти по устьевому давлению и по формуле Лапласа-Бабинэ, то для оценки температуры газа на глубине сотен метров необходимо производить спуско-подъемные операции (СПО) спаренного манометра-термометра. Очевидно то, что необходимость СПО глубинного прибора дает возможность определения уровня жидкости путем прямых измерений характеристик среды, в которой находится регистрирующее устройство.

Для устранения данного противоречия по патенту РФ на изобретение [27] часть газа из МП перепускается в камеру известного объема, фиксируется изменение давления благодаря изотермическому расширению газа. Далее по двум состояниям газа с помощью уравнения Бойля-Мариотта определяется глубина уровня жидкости. По изобретению в качестве среднего давления газовой среды используется давление газа в МП в устьевой зоне скважины без учета повышения давления с глубиной по известной экспоненте барометрического нивелирования. Для устранения этого недостатка необходимо рассматривать среднее значение давления газа в МП, но для определения давления газа на границе с жидкой фазой по формуле Лапласа-Бабинэ необходимо знать вертикальную координату ствола скважины от устья до уровня жидкости, которая и является неизвестной величиной. Для выхода из этого положения по изобретению [28] предложен итерационный метод поиска уровня жидкости в МП, заключающийся в том, что на первом этапе в указанную формулу подставляют уровень, соответствующий глубине подвески насоса, находят уточненный уровень жидкости по формуле Бойля-Мариотта, который опять используют для расчетов на втором этапе. Расчеты ведут до приведения уровня жидкости к одной постоянной величине. 
Температура среды в межтрубном пространстве скважины также может стать информативной величиной благодаря различной теплопроводности ПНГ и нефти в добывающих скважинах. В изобретении [29] это положение использовано для оценки состояния скважины, эксплуатируемой для добычи высоковязкой нефти с высокой температурой. Авторы изобретения оценивают положение уровня нефти в МП скважины с высокой температурой $\left(90-140{ }^{\circ} \mathrm{C}\right)$ по первому скачку температуры не менее, чем на $10^{\circ} \mathrm{C}$ в зависимости температуры среды в межтрубном пространстве от глубины измерения. Чувствительный элемент в виде оптоволоконного кабеля марки КОБ1400-тип4 предварительно размещают на стационарной основе в МП скважины, и по его данным контролируют положение уровня нефти, находящейся между обсадной колонной и насосно-компрессорными трубами.

Для скважин со штанговым плунжерным насосом специалисты из КНР рассмотрели возможность использования динамограмм, снятых на устье скважины, для диагностики положения уровня жидкости в межтрубном пространстве скважины [30, 31]. Расчетная формула в виде отношения содержит в числителе разницу между нагрузками на полированный шток в верхнем и нижнем положении плунжера насоса, в знаменателе - произведение площади сечения плунжера, плотности нефти в МП и ускорения свободного падения. По нашему мнению, способ применим только в водозаборных скважинах, в которых вода не содержит растворенного газа и имеет постоянную плотность по всей высоте в межтрубном пространстве скважины.

\section{Датчики давления для оценки уровня жидкости в скважинах}

В нефтегазодобывающем управлении «Чекмагушнефть» ОАО «АНК «Башнефть» в период 1990-2010 гг. был накоплен большой опыт по спуско-подъемным операциям спаренных манометров-термометров в пьезометрические и нефтедобывающие скважины. Одной из целей таких исследований было определение расположения водонефтяного контакта в открытом стволе или межтрубном пространстве скважины. Дополнительно отбирались пробы скважинной жидкости с разных глубин погружения прямоточного пробоотборника. Комплекс проведенных работ по скважине позволял однозначно идентифицировать положение водонефтяного контакта в скважине. Примерно такой же механизм исследований описан в [32], когда по данным манометра, спускаемого в скважину, определяют динамический уровень жидкости в межтрубном пространстве.

Выше было отмечено, что спуско-подъемные операции глубинных приборов относятся к сложным и не всегда возможным техническим процедурам на скважинах. Например, спуск прибора в межтрубное пространство скважины с глубинным электроцентробежным насосом совершенно невозможен из-за наличия в этом пространстве силового многожильного кабеля питания погружного электродвигателя установки.
Необходимость установки стационарного датчика давления в зоне глубинного электроцентробежного насоса отмечена в [1]. Сегодня термоманометрические системы помогают решать персоналу нефтяных компаний широкий круг задач эксплуатации системы «пласт-скважина-насос», но, как уже отмечалось во введении, по единственному датчику давления нельзя судить о положении уровня жидкости в скважине. Поэтому датчиков на стационарной основе должно быть несколько. Эта идея указана в работе [28].

Датчики давления в МП скважины располагают равномерно от устья до глубинного насоса так, чтобы вертикальная составляющая между ними была равна 100-150 м. Расположение датчиков давления на условно вертикальной скважине приведено на рис. 3 . Часть датчиков находятся в газовой среде, в которой давление с глубиной незначительно растет согласно формуле Лапласа-Бабинэ. Это видно по данным рис. 4 , где приведена зависимость давления от глубины пьезометрической скважины. Зависимость получена путем проведения спуско-подьемной операции глубинного манометра-термометра от устья до отметки 1000 м.

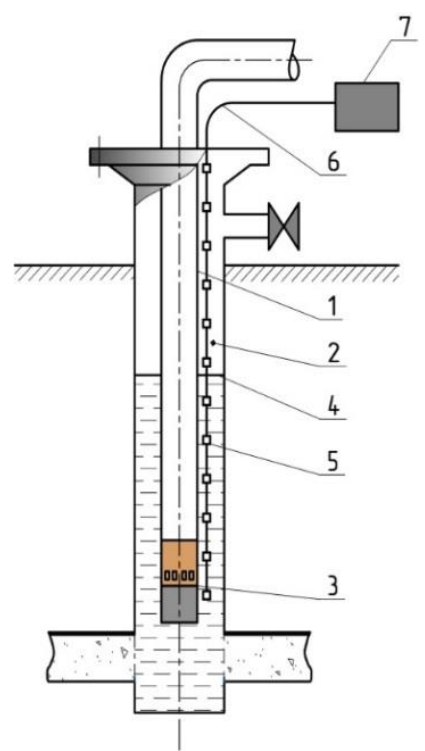

Рис. 3. Датчики давления для контроля уровня в скважине: 1 - колонна лифтовых труб; 2 межтрубное пространство скважины; 3 - глубинный насос; 4 - динамический уровень жидкости; 5 - датчики давления; 6 - кабель электропитания с функиией обратной связи; 7 - станция управления скважины

Fig. 3. Pressure sensors for continuous monitoring of the dynamic level of the well: 1 - string of elevator pipes; 2 - annular space of the well; 3 -downhole pump; 4 -dynamic level (gas-liquid section); 5 pressure sensors; 6 -armored communication cable; 7 -well control station

При вхождении манометра в зону нефти ниже глубины 466 м давление значительно растет, и в среднем градиент давления в жидкостной среде составляет 0,7 МПа на 100 м. По этой информации кон- 
троллер станции управления скважины выявляет область с попутным нефтяным газом, находит уравнение прямой зависимости давления от глубины установки датчика давления:

$$
P_{\text {газ.ф. }}=0,0001 \cdot H+0,7996 \text {. }
$$

Аналогичное уравнение контроллер выдает по данным датчиков, находящихся в жидкостной фазе МП скважины:

$$
P_{\text {жид.ф. }}=0,007 \cdot H-2,4127 .
$$

Совместное рассмотрение уравнений (5) и (6) позволяет оценить уровень жидкости на глубине 465,5 м.

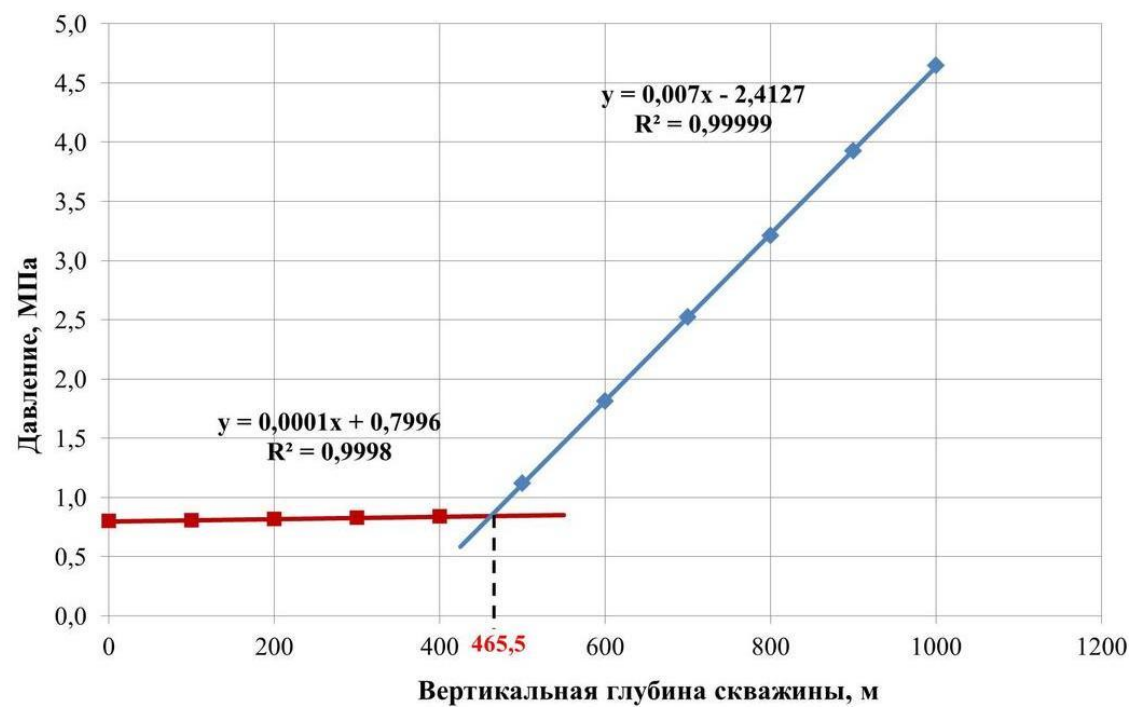

Рис. 4. Определение уровня жидкости в скважине

Fig. 4. Determination of the level of fluid in the well

Приведенный пример показывает надежность и информативность стационарных датчиков давления, расположенных в кольцевом пространстве скважины от устья до глубинного насоса. Для определения нижней границы газовой среды и дальнейшей интерпретации полученной информации в работе [33] предложено наблюдать за коэффициентом корреляции зависимости давления от глубины. Переход газовой среды в жидкую фазу влечет за собой резкое снижение коэффициента корреляции исследуемой зависимости.

Аналогичные результаты по использованию стационарных датчиков давления в составе оптоволоконной линии в скважине представлены в докладе группы авторов [34]. Согласно докладу, концерн Shell и компания SmartFibers в оптоволоконной линии разместили мембранные манометры, чувствительные к изменению давления в окружающей среде. Величина деформации манометра оценивается путем измерения длины волны, отраженной от оптоволоконной брегговской решетки. Технология успешно испытана в период с 2010 по 2014 гг. в нескольких скважинах, количество датчиков давления варьировало от 9 до 14 .

В статье было отмечено, что давление попутного нефтяного газа в МП растет по экспоненциальной зависимости. Добавим, что и давление жидкости от динамического уровня до глубинного насоса будет расти нелинейно из-за различного содержания свободного газа в нефти по глубине скважины. Наиболее полно состояние нефти с газом в межтрубном пространстве нефтедобывающей скважины описано в работе [35]. По мнению авторов, в узком межтрубном пространстве существует два встречных потока нефти: вверх движется пластовая нефть со значительным газосодержанием, а вниз - тяжелая нефть с минимальным содержанием газа. Несмотря на существование такого сложного состояния нефти в МП, очевидно, что плотность нефти с растворенным газом вблизи насоса будет выше плотности нефти с окклюдированным и свободным газом вблизи межфазной поверхности нефти и газа. В связи с этим интерпретацию данных от датчиков давления, равномерно расположенных от устья скважины до насоса можно проводить не по двум массивам данных: в газовой и жидкостной средах, а по «скользящей» информации. По данным первых (верхних) 3-4 датчиков давления определяется коэффициент корреляции прямолинейной зависимости давления от вертикальной составляющей скважины, далее информация по первому датчику удаляется, но добавляется давление по нижележащему датчику, расчет корреляции нового массива данных повторяется. Расчеты, проведенные по данным трех скважин [33], показали, что предложенный математический алгоритм позволяет идентифицировать межфазную поверхность с приемлемой точностью в несколько метров.

\section{Выводы}

1. Динамический уровень жидкости даже при наличии термо-манометрической системы в скважине продолжает выполнять важную информационную роль в процессе эксплуатации системы «пластскважина-насос». Основным методом определения уровня жидкости во всех видах эксплуатаци- 
онных скважинах нефтедобывающих компаний является звукометрический способ, основанный на распространении акустической волны в газовой среде. Из-за изменений в системе разработки вблизи скважины, неконтролируемой работы перепускного клапана на устье скважины и меняющегося давления состав попутного нефтяного газа в межтрубном пространстве не является постоянной величиной, поэтому подавляющее большинство измерений уровня жидкости в нефтедобывающих скважинах производятся с определенной погрешностью.

2. Для водозаборных и нефтедобывающих скважин с минимальным газосодержанием разработаны алгоритмы измерения уровня жидкости, основанные на распространении акустической волны в жидкой среде - воде или нефти. В этих алгоритмах граница между газом и жидкостью идентифицируется как физическая граница разных сред благодаря постоянному нахождению дополнительных тел на этой границе, и этим устраняется существующая сегодня неопределенность в диагностике динамического уровня жидкости звукометрическим методом.

3. Наиболее перспективным и универсальным для скважин любого назначения является способ определения динамического уровня жидкости, основанный на наличии в межтрубном пространстве определенного количества датчиков давления. Наши исследования показали, что уровень жидкости диагностируется с минимальной погрешностью в постоянном режиме времени и без участия персонала предприятия. Способ повышает информационную обеспеченность скважины и является одной из составных частей «интеллектуальной» скважины.

\section{СПИСОК ЛИТЕРАТУРЫ}

1. Щуров В.И. Технология и техника добычи нефти. - М.: Недра, 1983. $-510 \mathrm{c}$.

2. Зейгман Ю.В., Гумеров О.А. Эффективность эксплуатации электроцентробежных насосов в скважинах. - Уфа: ООО «Монография», 2006. - 88 c.

3. Персиянцев М.Н. Добыча нефти в осложненных условиях. М.: ООО «Недра-Бизнесцентр», 2000. - 653 с.

4. Мищенко И.Т., Леонов И.В. Основы физико-математической модели системы «эксплуатационный объект - добывающая скважина - установка ЭЦН» // Вестник Ассоциации буровых подрядчиков. - 2011. - № 3. - С. 36-40.

5. Денисламов И.З., Гафаров Ш.А., Еникеев Р.М. Интерпретация данных современной телеметрии скважинных электроцентробежных насосов // Нефтегазовые технологии и новые материалы. Проблемы и решения: сб. науч. тр. - Уфа: ООО «Монография», - 2014. - Вып. 3 (8). - С. 243-250.

6. Сухоруков М.П., Торгаева Д.С., Мамлина В.В. Сравнительный анализ методов определения динамического уровня жидкости в межтрубном пространстве нефтяной скважины // Электронные средства и системы управления: XIII Международная научно-практическая конференция, посвященная 55-летию ТУСУРа. - Томск, 2017. - С. 178-181.

7. Wei Jia, Wei Zhou, Tai-fu Li. A review of dynamic fluid level detection for oil well // Mechanics and Materials. - 2014. V. $456 .-$ P. $582-586$

8. Burgstaller C. New approaches of using fluid level data for production optimization and reservoir engineering applications //

\section{Заключение}

Контролирование динамического уровня жидкости в межтрубном пространстве нефтедобывающих и водозаборных скважин и давления на приеме глубинного насоса обеспечивает эффективность работы системы «пласт-скважина-насос» по нескольким причинам. Неизменность уровня жидкости будет наблюдаться при равенстве притока пластовой жидкости и производительности глубинного насоса. Наблюдение за плотностью газированной нефти в межтрубном пространстве как результат такого информационного обеспечения позволит косвенно судить о содержании свободного газа на приеме насоса и предупреждать аварийные ситуации в эксплуатации электроцентробежного насоса, связанные со срывом подачи пластовой продукции и перегревом установки в целом насоса или погружного электродвигателя.

Сегодня данные термо-манометрических систем и переносных уровнемеров типа Микон и Суддос анализируются на рабочих местах геологов и технологов нефтегазодобывающих компаний на момент их поступления, а это происходит с различной периодичностью. Датчики давления, находящиеся в скважине от устья до насоса на стационарной основе, устраняют этот недостаток, дают возможность оперативно и без участия персонала предприятия принимать технические решения по изменению режима эксплуатации глубинного насоса, а значит и всей рассматриваемой системы взаимодействия продуктивного пласта, скважины и глубинного насоса.

Работа выполнена в рамках госзадания в сфере научной деятельности № FEUR-2020-0004. Наименование проекта «Решение актуальных задач и исследование процессов в нефтехимических производствах, сопровождаюшихся течениями многофазных сред».

78th EAGE Conference and Exhibition. - Vienna, Austria, 30 May-2 June 2016.

9. Fully automated fluid level measurement tool / G. Sam, C. Burgstaller, M. Kaestenbauer, E. Chevelcha // SPE Asia Pacific Oil and Gas Conference and Exhibition. - Jakarta, Indonesia, 20-22 September 2011.

10. Song C., Guan X. The monitoring system design of oil well dynamic fluid level // Journal of Physics: 4th International Conference on Intelligent Computing and Signal Processing. Xi'an, China, 29-31 March 2019.

11. Пугачев Е.В., Налимов Г.П., Гаус П.О. Определение уровня жидкости и скорости звука в затрубном пространстве добывающей скважины // Нефтяное хозяйство. - 2003. - № 2. C. $50-52$.

12. Исследование состава флюидов и процессов в межтрубном пространстве нефтедобывающих скважин / И.З. Денисламов, Ш.А. Гафаров, П.А. Засов, А.И. Денисламова // Нефтепромысловое дело. - 2018. - № 4. - С. 38-42.

13. Налимов К.Г. Информационная система эхометрирования многоимпульсными сигналами для определения уровня жидкости в нефтедобывающих скважинах: автореф. дис. ... канд. техн. наук. - Томск, 2007. $-23 \mathrm{c}$.

14. Lieberman S. Automated continuous fluid level monitoring // SPE Production Operations Symposium. - Oklahoma City, USA, 16-19 April 2005.

15. Study on the measurement method of oil well's dynamic liquid level based on air column resonance / W. Zhou, L. Gan, P. Zhou, T. Li, X. Gu // IOP Conference Series: Earth and Environmental Science. - Zhuhai, China, 28-30 April 2017. 
16. Implementation of Tikhonov regularization in oil well liquid level reading data / N. Irianto, S. Rachmat, L. Mucharam, W.S. Indratno // Modern Applied Science. - 2017 - V. 11. - № 10. - P. 81-90.

17. Zhou W., Liu J., Gan L. Dynamic liquid level detection method based on resonant frequency difference for oil wells // Turkish Journal of Electrical Engineering and Computer Science. - 2018. V. 26 (6). - P. 2967-2975.

18. Коротаев Ю.П., Ширковский А.И. Добыча, транспорт и подземное хранение газа. - М.: Недра, 1984. - 487 с.

19. Способ определения уровня жидкости в скважинах: пат. Рос. Федерация № 2038473, заявл. 01.02.1993; опубл. 27.06.1995. Бюл. № 18. - С. 184.

20. Способ определения уровня жидкости в скважине: пат. Рос. Федерация № 2612704, заявл. 10.03.2016; опубл. 13.03.2017. Бюл. № 8.

21. Способ определения уровня жидкости в водозаборной скважине: пат. Рос. Федерация № 2623756, заявл. 16.05.2016 опубл. 29.06.2017. - Бюл. № 19.

22. Технологии подготовки сверхвязкой нефти Татарстана Ф.Р. Губайдуллин, Р.З. Сахабутдинов, Т.Ф. Космачева, С.Н. Судыкин, А.Н. Судыкин. - Казань: Центр инновационных технологий, 2015. - 280 c.

23. Chen D.F., Han X.L., Jing Y. Discuss on survey method for liquid level of oil well // WellTesting. - 2008. - V. 17. - P. 60-62.

24. Моисеев В.Н. Применение геофизических методов в процессе эксплуатации скважин. - М.: Недра, 1990. - 240 с.

25. Кузнецов Г.С., Леонтьев Е.И., Резванов Р.А. Геофизические методы контроля разработки нефтяных и газовых месторождений. - М.: Недра, 1991. -223 с.

26. Wu D.N., Liu P.L. To test the liquid level of a pump well by a material balance method // Well Testing. - 2003. - V. 12. - P. 31-33

27. Способ измерения уровня жидкости в скважине и устройство для его осуществления: пат. Рос. Федерация № 2232267, заявл. 07.10.2002; опубл. 10.07.2004. Бюл. № 19. - С. 500-501.
28. Способ определения уровня жидкости в скважине: пат. Рос. Федерация № 2559979, заявл. 08.07.2014; опубл. 20.08.2015. Бюл. № 23.

29. Способ определения уровня жидкости в нефтяной скважине с высокой температурой, добывающей сверхвязкую нефть: пат. Рос. Федерация № 2494248. Заявл. 19.10.2012; опубл. 27.09.2013. Бюл. № 27. - С. 282.

30. Liu Z., Wang H., Yang D. Determination of real-time dynamic fluid levels by analysis of the dynamometer card // Canadian International Petroleum Conference. - Calgary, Alberta, January 2007.

31. Real time calculation of fluid level using dynamometer card of sucker rod pump well / H. Yang, L. Mu, Y. Zeng, W. Huang, H. Xin, Q. Gan, M. Li, L. Zhang, E. Han // International Petroleum Technology Conference. - Kuala Lumpur, Malaysia, 10-12 December 2014.

32. Zhang H. Discussion of detecting fluid level by pressure gauge // Well Testing. -2003 . - V. 12. - P. 81-84

33. Денисламов И.З., Бисенова А.А., Еникеев Р.М. Обучающие алгоритмы для интеллектуальной скважины // Время колтюбинга. - 2015. - № 2. - С. 56-60.

34. Development and field application of a permanent fiberoptic wellbore fluid level monitoring system / C. Staveley, C. Djyle, C. Coetzee, A. Franzen, H. Den Boer, A. van Rooyen, W. Birch, A.B. Biderkab, E. Moes // Abu Dhabi International Petroleum Exhibition \& Conference. - Abu Dhabi, UAE, 13-16 November 2017.

35. Разработка нефтяных месторождений. Т. 2. Эксплуатация добывающих и нагнетательных скважин / под ред. Н.И. Хисамутдинова, Г.З. Ибрагимова. - М.: ВНИИОЭНГ, 1994. - 272 с.

Поступила: 07.10.2019 г.

\section{Информация об авторах}

Денисламов И.З., кандидат технических наук, доцент кафедры разработки и эксплуатации нефтяных и газонефтяных месторождений Уфимского государственного нефтяного технического университета.

Гималтдинов И.К., доктор физико-математических наук, профессор, заведующий кафедрой физики Уфимского государственного нефтяного технического университета; член-корреспондент Академии Наук Республики Башкортостан.

Якубов Р.Н., кандидат технических наук, доцент кафедры разработки и эксплуатации нефтяных и газонефтяных месторождений Уфимского государственного нефтяного технического университета.

Денисламова А.И., студент кафедры разработки и эксплуатации нефтяных и газонефтяных месторождений Уфимского государственного нефтяного технического университета. 
UDC 621.316 .71

\title{
TECHNICAL SOLUTIONS FOR ESTIMATING LIQUID LEVEL IN OIL AND WATER WELLS
}

\author{
Ildar Z. Denislamov', \\ denislamoviz@mail.ru
}

Ilias K. Gimaltdinov1,2, iljas_g@mail.ru

Ravil N. Yakubov ${ }^{1}$, rnyakubov@gmail.com

\author{
Aliya I. Denislamova1, \\ denislamova2014alia@mail.ru \\ 1 Ufa State Petroleum Technological University, \\ 1, Kosmonavtov street, Ufa, 450062, Russia. \\ 2 Academy of Sciences of the Republic of Bashkortostan, \\ 15 , Kirov street, Ufa, 450008, Russia
}

The relevance of the research follows from the need to assess the dynamic level of liquid in oil producing and water wells with the necessary frequency, which can be provided as one of the functions of an intelligent well.

The aim of the research is to search for alternative methods for determining the liquid level in the annulus of wells without involving personnel in the well zone.

Objects: oil producing wells equipped with pressure sensors, generators and receivers of acoustic waves and secondary instruments for transmitting information to the workplaces of the personnel of the enterprise.

Methods: based on the well-known laws of physical hydrodynamics and methods of mathematical statistics.

Results. The soundometric method for determining the dynamic liquid level in the annulus of a well has an error in measurements in existing oil wells due to the inconstancy of the composition of associated petroleum gas in time and in the depth of the tubing at a fixed point in time.

Key words:

Gas composition, well, annulus, fluid level, pressure sensor, electric centrifugal pump, tubing, sound wave.

This work was carried out as part of the state assignment in the field of scientific activity no. FEUR-2020-0004. The name of the project is «Solving urgent problems and researching processes in petrochemical industries accompanied by multiphase flow».

\section{REFERENCES}

1. Shchurov V.I. Tekhnologiya i tekhnika dobychi nefti [Technology and technique of oil production]. Moscow, Nedra Publ., 1983. $510 \mathrm{p}$.

2. Zeigman Yu.V., Gumerov O.A. Effektivnost ekspluatatsii elektrotsentrobezhnykh nasosov $v$ skvazhinakh [Efficiency of operation of electric centrifugal pumps in wells]. Ufa, Monografiya Publ., 2006. 88 p.

3. Persiyantsev M.N. Dobycha nefti v oslozhnennykh usloviyakh [Oil production in the complicated conditions]. Moscow, NedraBiznestsentr Publ., 2000. 653 p.

4. Mishchenko I.T., Leonov I.V. Fundamentals of physicalmathematical model of «development target - producing well ESP» system. Bulletin of the Association of Drilling Contractors, 2011, no. 3, pp. 36-40. In Rus.

5. Denislamov I.Z., Gafarov Sh.A., Enikeev R.M. Interpretatsiya dannykh sovremennoy telemetrii skvazhinnykh elektrotsentrobezhnykh nasosov [Data telemetry of downhole electric centrifugal pumps interpretation]. Neftegazovye tekhnologii i novye materialy. Problemy i resheniya [Oil and gas technologies and new materials. Problems and solutions]. Ufa, Monografiya Publ., 2014. Vol. 3 (8), pp. 243-250.

6. Sukhorukov M.P., Torgaeva D.S., Mamlina V.V. Sravnitelny analiz metodov opredeleniya dinamicheskogo urovnya zhidkosti v mezhtrubnom prostranstve neftyanoy skvazhiny [Comparative analysis of methods of determination of dynamic level of liquid in the annular space of oil wells]. Elektronnye sredstva i sistemy upravleniya. XIII Mezhdunarodnaya nauchno-prakticheskaya konferentsiya, posvyashchennaya 55-letiyu TUSURa [Electronic tools and systems management. XIII international scientific-practical conference dedicated to the $55^{\text {th }}$ anniversary of TUSUR]. Tomsk, 2017. pp. 178-181.

7. Wei Jia, Wei Zhou, Tai-fu Li. A review of dynamic fluid level detection for oil well. Mechanics and Materials, 2014, vol. 456, pp. 582-586.

8. Burgstaller C. New approaches of using fluid level data for production optimization and reservoir engineering applications. $78^{\text {th }}$ EAGE Conference and Exhibition. Vienna, Austria, 30 May2 June 2016.

9. Sam G., Burgstaller C., Kaestenbauer M., Chevelcha E. Fully automated fluid level measurement tool. Asia Pacific Oil and Gas Conference and Exhibition. Jakarta, Indonesia, 20-22 September 2011.

10. Song C., Guan X. The monitoring system design of oil well dynamic fluid level. Journal of Physics: $4^{\text {th }}$ International Conference on Intelligent Computing and Signal Processing. Xi'an, China, 29-31 March 2019.

11. Pugachev E.V., Nalimov G.P., Gaus P.O. Determination of the liquid level and sound speed in the hole clearance of the producing well. Oil industry, 2003, no. 2, pp. 50-52. In Rus.

12. Denislamov I.Z., Gafarov Sh.A., Zasov P.A., Denislamova A.I. Investigation of fluids composition and processes in the tubingcasing annulus of oil producing wells. Oilfield engineering, 2018, no. 4, pp. 38-42. In Rus.

13. Nalimov K.G. Informatsionnaya sistema ekhometrirovaniya mnogoimpulsnymi signalami dlya opredeleniya urovnya zhidkosti $v$ neftedobyvayushchikh skvazhinakh. Avtoreferat Diss. Kand. nauk [Information system of multi-pulse echometry signals to determine the liquid level in oil wells . Cand. Diss. Abstract]. Tomsk, 2007. $23 \mathrm{p}$. 
14. Lieberman S. Automated continuous fluid level monitoring. SPE Production Operations Symposium. Oklahoma City, USA, 16-19 April 2005.

15. Zhou W., Gan L., Zhou P., Li T., Gu X. Study on the measurement method of oil well's dynamic liquid level based on air column resonance. IOP Conference Series: Earth and Environmental Science. Zhuhai, China, 28-30 April 2017.

16. Irianto N., Rachmat S., Mucharam L., Indratno W.S. Implementation of Tikhonov regularization in oil well liquid level reading data Modern Applied Science, 2017, vol. 11, no. 10, pp. 81-90.

17. Zhou W., Liu J., Gan L. Dynamic liquid level detection method based on resonant frequency difference for oil wells. Turkish Journal of Electrical Engineering and Computer Science, 2018, vol. 26 (6), pp. 2967-2975.

18. Korotaev Yu.P., Shirkovskii A.I. Dobycha, transport i podzemnoe khranenie gaza [Production, transport and underground storage of gas]. Moscow, Nedra Publ., 1984. 487 p.

19. Vygodskii E.M., Sultanov V.G., Gafarov Sh.A., Ivanov S.V. Sposob opredeleniya urovnya zhidkosti v skvazhinakh [Method for determining the liquid level in wells]. Patent RF, no. 2038473 , 1995.

20. Denislamov I.Z., Ishbaev R.R., Yafaev B.M., Denislamova G.I. Sposob opredeleniya urovnya zhidkosti $v$ skvazhine [Method for determining the fluid level in the well]. Patent RF, no. 2612704, 2017.

21. Denislamov I.Z., Zeigman Yu.V., Denislamova G.I. Sposob opredeleniya urovnya zhidkosti $v$ vodozabornoi skvazhine [Method for determining the liquid level in a water well]. Patent RF, no. $2623756,2017$.

22. Gubaidullin F.R., Sahabutdinov R.Z., Kosmacheva T.F., Sudykin S.N Sudykin A.N. Tekhnologii podgotovki sverkhvyazkoy nefti Tatarstana [Technology of preparation of extra-viscous oil fields in Tatarstan]. Kazan, Tsentr innovatsionnykh tekhnologii Publ., 2015. $280 \mathrm{p}$.

23. Chen D.F., Han X.L., Jing Y. Discuss on survey method for liquid level of oil well. WellTesting, 2008, vol. 17, pp. 60-62.

24. Moiseev V.N. Primenenie geofizicheskikh metodov $v$ protsesse ekspluatatsii skvazhin [Application of geophysical methods in well operation]. Moscow, Nedra Publ., 1990. 240 p.

25. Kuznetsov G.S., Leontev E.I., Rezvanov R.A. Geofizicheskie metody kontrolya razrabotki neftyanykh $i$ gazovykh mestorozhdenii [Geophysical methods of control of development of oil and gas fields]. Moscow, Nedra Publ., 1991. 223 p.
26. Wu D.N., Liu P.L. To test the liquid level of a pump well by a material balance method. Well Testing, 2003, vol. 12, pp. 31-33.

27. Abramov G.S., Barychev A.V., Kayurov K.N., Lukyanov E.E. Sposob izmereniya urovnya zhidkosti v skvazhine i ustroystvo dlya ego osushchestvleniya [Method for measuring the level of fluid in the well and the device for its implementation]. Patent RF, no. 2232267, 2004.

28. Denislamov I.Z., Enikeev R.M. Sposob opredeleniya urovnya zhidkosti $v$ skvazhine [Method for determining the fluid level in the well]. Patent RF, no. 2559979, 2015.

29. Ibragimov N.G., Salikhov I.M., Akhmadullin R.R., Akhmetzyanov M.S., Aslamov N.A. Sposob opredeleniya urovnya zhidkosti v neftyanoy skvazhine s vysokoy temperaturoy, dobyvayushchey sverkhvyazkuyu neft [Method for determining the liquid level in a high-temperature oil well producing ultra-viscous oil]. Patent RF, no. 2494248, 2013.

30. Liu Z., Wang H., Yang D. Determination of real-time dynamic fluid levels by analysis of the dynamometer card. Canadian International Petroleum Conference. Calgary, Alberta, January 2007.

31. Yang H., Mu L., Zeng Y., Huang W., Xin H., Gan Q., Li M., Zhang L., Han E. Real time calculation of fluid level using dynamometer card of sucker rod pump well. International Petroleum Technology Conference. Kuala Lumpur, Malaysia, 10-12 December 2014.

32. Zhang H. Discussion of detecting fluid level by pressure gauge. Well Testing, 2003, vol. 12, pp. 81-84.

33. Denislamov I.Z., Bisenova A.A., Enikeev R.M. Learning algorithms for smart wells. Coiled Tubing Times, 2015, no. 2, pp. 56-60. In Rus.

34. Staveley C., Djyle C., Coetzee C., Franzen A., Den Boer H., van Rooyen A., Birch W., Biderkab A.B., Moes E. Development and field application of a permanent fiberoptic wellbore fluid level monitoring system. Abu Dhabi International Petroleum Exhibition \& Conference. Abu Dhabi, UAE, 13-16 November 2017.

35. Razrabotka neftyanykh mestorozhdenii. T. 2. Ekspluatatsiya dobyvayushchikh i nagnetatelnykh skvazhin [Oil field development. Vol. 2. Operation of production and injection wells.] Eds. N.I. Khisamutdinova, G.Z. Ibragimova. Moscow, VNIIOENG Publ., 1994. $272 \mathrm{p}$

Received: 7 October 2019.

\section{Information about the authors}

Ildar Z. Denislamov, Cand. Sc., associate professor, Ufa State Petroleum Technological University.

Ilias K. Gimaltdinov, Dr. Sc., professor, Ufa State Petroleum Technological University; corresponding member, Academy of Sciences of the Republic of Bashkortostan.

Ravil N. Yakubov, Cand. Sc., associate professor, Ufa State Petroleum Technological University. Aliya I. Denislamova, bachelor student, Ufa State Petroleum Technological University. 